\title{
PENGARUH GAYA KEPEMIMPINAN DAN LINGKUNGAN \\ KERJA TERHADAP KINERJA KARYAWAN PADA \\ PT BPR AGRO CIPTA ADIGUNA PARE
}

\author{
Amelinda Putri; Nurlaely; Heri Subagyo \\ Fakultas Ekonomi - Universitas Kadiri, Kediri \\ ”Email : nurlaely@unik-kediri.ac.id
}

\begin{abstract}
Effective saving style can be used as an example and good example for members or people who are led and able to motivate to achieve the goals of the company employees of PT BPR Agro Cipta Adiguna Pare. The method of analyzing this research data is Multiple Linear Regression Test, Classical Assumption Test, and / or Hypothesis Test. The results of this study Leadership Style (X1) on the positive so significant effect on Employee Performance the results of the test t the value is significant 0.003, in the Work Environment (X2) positively or significantly affected the Employee Performance the results $t$ test value is significant His leadership style and work environment are simultaneously positively and significantly affected by Employee Performance as seen from the results of the $F$ Test with sig values $(0,000<0,05)$ Regression equation obtained results $Y=2,253 X 1+0,1999 X 2+e$

Keywords: Leadership Style, Work Environment and Employee Performance
\end{abstract}

\begin{abstract}
ABSTRAK
Gaya kepemimpan yang efektif dapat dijadikan contoh dan tauladan yang baik bagi anggota atau orang yang dipimpin serta mampu memotivasi untuk mencapai tujuan perusahaan karyawan PT BPR Agro Cipta Adiguna Pare. Metode analisis data penelitian ini Uji Regresi Linier Berganda, Uji Asumsi Klasik, dan atau Uji Hipotesis. Hasilnya penelitian ini Gaya Kepemimpinan (X1) terhadap pengaruh yang positif sehingga signifikan terhadap Kinerja Karyawan hasilnya uji t nilainya disignifikan 0,003, di Lingkungan Kerja (X2) terpengaruh positif dan atau signifikan terhadap Kinerja Karyawan hasilnya Uji t nilainya disignifikan 0,001. Gaya kepemimpinannya dan dilingkungan kerjanya secara simultan terpengaruh positif dan tersignifikan terhadap Kinerja Karyawan terlihat dari hasilnya Uji F dengan nilai sig $(0,000<0,05)$ Persamaan regresi diperoleh hasil $\mathrm{Y}=2,253 \mathrm{X} 1+0,1999 \mathrm{X} 2+\mathrm{e}$

Kata Kunci : Gaya Kepemimpinan, Lingkungan Kerja dan Kinerja Karyawan
\end{abstract}

\section{PENDAHULUAN}

Perusahaan harus mampu melalui perencanaan, perorganisasian, pengendalian sumber daya organisasi dan kepemimpinan. Faktor kinerja karyawan yaitu berkaitan dengan lingkungan kerja yang mendukung adanya sebuah organisasi serta gaya kepemimpinan seorang pemimpin perusahaan tersebut.Kepuasan kerja jika di pengaruhi lingkungan kerja yang konduktif akan lebih semangat (Widodo, 2014).Tanpa adanya motivasi kerja kepemimpinan transformasional dan kepmimpinan transaksional 
mempunyai pengaruh positif mengenai kinerja karyawan (Handoyo laura natalia, Hamid Djamhud, 2015).Dampak dari kepemimpinan juga motivasi terhadap kepuasan kerja secara bersama-sama(Langi, Saerang, \& Worang, 2015) Karena keduannya termasuk faktor yang memegang peran penting dalam mencapai tujuan perusahaan.motovasi berpengaruh positif signifikan ,motivasi juga mampu meningkatkan pengaruh kepemimpinan (Rahayu \& Ruhamak, 2017; Satriyono, 2017). kurang sadar dalam kepemilikan usaha dan pemakaian teknologi informasi (Putra, Yudiarto Perdana, heryanto, 2017).Seorang pemimpin harus dapat mengayomi bawahanya dengan baik secara bersama sama(Putra, Febri Arin, Musad mochammad al, 2016) .Gaya kepemimpinan ,lingkungan kerja,motivasi kerja,kinerja pegawai perlu digunakan untuk meningkatkan kerja(Darumeutia.Anisah, 2017).

PT BPR Agro Cipta Adiguna Pare, perusahaan ini sering melakukan pergantian pimpinan atau direktur sesuai kesepakatan yang dilakukan di rapat tahunan atau disenut dengan Rapat Umum Pemegang Saham (RUPS). Seperti informasi yang saya dapatkan dari salah satu karyawannya, pada tahun 2015 sampai dengan 2016 dipimpin oleh ibu Eni Karyawati S.E . Beliau sebelumnya adalah staf/karyawan tetap di PT BPR Agro Cipta Adiguna Pare yang telah naik jabatan. Masa jabatan beliau hanya satu tahun. tahun 2017 digantikan oleh ibu Yuli Srihandayani, S.E.

Dengan melihat permasalahan yang ada di PT BPR Agro Cipta Adiguna Pare, maka setelah pergantian pimpinan diminta adanya gaya kepemimpinan yang sesuai dengan keadaan diperusahaan.

Berdasarkan latar yang di teliti, peneliti mengambil simpulan judul "Pengaruh Gaya Kepemimpinan dan Lingkungan Kerja Terhadap Kinerja Karyawan di PT BPR AGRO CIPTA ADIGUNA PARE KEDIRI". 


\section{TINJAUAN PUSTAKA}

\section{Penelitian Terdahulu}

Tabel 1. Penelitian Terdahulu

\begin{tabular}{|c|c|c|c|c|}
\hline No & $\begin{array}{c}\text { Nama } \\
\text { Peneliti }\end{array}$ & Judul & $\begin{array}{c}\text { Variabel dan Alat } \\
\text { Analisis }\end{array}$ & Hasil Penelitian \\
\hline 1 & $\begin{array}{l}\text { A.Ivan } \\
\text { Sanjaya } \\
(2016)\end{array}$ & $\begin{array}{l}\text { Pengaruh } \\
\text { Kepemimpinan, } \\
\text { Motivasi Dan } \\
\text { Lingkungan } \\
\text { Kerja Terhadap } \\
\text { Kinerja } \\
\text { Karyawan (Studi } \\
\text { pada PT. } \\
\text { Perkebunan } \\
\text { Nusantara VII } \\
\text { Pematang Kiwah } \\
\text { Natar) }\end{array}$ & $\begin{array}{l}\text { Jenis Penelitian: } \\
\text { Deskriptif } \\
\text { Kuantitatif } \\
\text { Variabel: } \\
\text { 1. Kepemimpinan } \\
\text { 2. Motivasi } \\
\text { 3. Lingkungan } \\
\quad \text { Kerja } \\
\text { 4. Kinerja } \\
\quad \text { karyawan } \\
\text { Alat Analisis: } \\
\text { Regresi Linier } \\
\text { Berganda }\end{array}$ & $\begin{array}{l}\text { Berdasarkan hasil uji t } \\
\text { (parsial) menunjukkan } \\
\text { bahwa variabel } \\
\text { kepemimpinan berpengaruh } \\
\text { signifikan terhadap kinerja } \\
\text { karyawan, variabel motivasi } \\
\text { berpengaruh tidak signifikan } \\
\text { terhadap kinerja karyawan } \\
\text { dan variabel lingkungan } \\
\text { kerja berpengaruh signifikan } \\
\text { terhadap kinerja karyawan. } \\
\text { Berdasarkan uji F (simultan) } \\
\text { menunjukkan bahwa variabel } \\
\text { kepemimpinan, motivasi dan } \\
\text { lingkungan kerja } \\
\text { berpengaruh signifikan } \\
\text { terhadap kinerja karyawan. }\end{array}$ \\
\hline 2 & $\begin{array}{l}\text { Febri Arin } \\
\text { Putra et al } \\
(2016)\end{array}$ & $\begin{array}{l}\text { Pengaruh Gaya } \\
\text { Kepemimpinan } \\
\text { Dan Lingkungan } \\
\text { Kerja Terhadap } \\
\text { Kinerja (Studi } \\
\text { pada Karyawan } \\
\text { Perusahaan } \\
\text { Daerah Air } \\
\text { Minum (PDAM) } \\
\text { Kota Malang) }\end{array}$ & $\begin{array}{l}\text { Jenis penelitian: } \\
\text { Kuantitatif } \\
\text { Variabel: } \\
\text { 1. Gaya } \\
\text { Kepemimpinan } \\
\text { 2. Lingkungan } \\
\text { kerja } \\
\text { 3. Kinerjanya } \\
\text { Karyawan } \\
\text { Alat Analisis: } \\
\text { Regresi Linier } \\
\text { Berganda }\end{array}$ & $\begin{array}{l}\text { Berdasarkan hasil analisis } \\
\text { regresi linier berganda } \\
\text { menunjukkan bahwa gaya } \\
\text { kepemimpinan direktif, gaya } \\
\text { kepemimpinan suportif, gaya } \\
\text { kepemimpinan partisipatif, } \\
\text { gaya kepemimpinan } \\
\text { berorientasi prestasi, dan } \\
\text { lingkungan kerja fisik } \\
\text { mempunyai pengaruh } \\
\text { signifikan terhadap kinerja } \\
\text { karyawan baik secara } \\
\text { simultan maupun parsial. Hal } \\
\text { ini ditunjukkan melalui hasil } \\
\text { uji simultan dan uji parsial } \\
\text { dengan nilai signifikansi < } \\
0,05 \text {. }\end{array}$ \\
\hline
\end{tabular}

\section{Pengertian Kepemimpinan}

Dari pengertian diatas kepemimpinan merupakan faktor yang sangat penting dan bagaimana caranya seseorang memimpin hingga dapat membawa kelompok kerja kearah keberhasilan yang maksimal. 
Menurut DuBrin (2005) pemimpin adalah berkomunikasi untuk mencapainya sebuah tujuan, caranya mempengaruhi orang lain dengan petunjuk, tindakannya menyebabkan orang lain harus bertindak dan timbulkan perubahan yang positif, kekuatan yang dinamis sangat penting untuk motivasi dan koordinasi organisasi di dalam rangka untuk mencapai tujuan, kemampuannya menciptakan rasa percaya diri dan dukungannya antara bawahan sehingga tujuannya di organisasi bisa tercapai. Faktornya lingkungan kerjanya ada 2 yaitu Faktor Lingkungan di tempat Kerja baik Fisik, maupun Faktor Lingkungan Kerjanya Non Fisik.

\section{Aspek Lingkungan Kerja}

Layanan kerja, kondisi kerja, hubungan dengan karyawan

\section{Faktor-faktor yang Mempengaruhi Kinerja Karyawan}

Mangkunegara (2000:67) mengatakan dengan prhatian dalam pengukuran didalam penilaian kinerja antara lain:

a. Kualitas kerja, yaitu dengan Ketelitian, kerapian, dan berkaitan hasil kerja terhadap mengabaikan total pekerjaan

b. Kuantitas Kerja, yaitu total dengan hasil kerja yang menghasilkan dibawah keadaannya yang normal.

c. Bertanggung jawab, adalah nunjukkan berapa besar karyawannya dapat bertanggungjawab hasil kerjanya, sarana prasarana digunakan beserta perilaku kerja.

d. Inisiatif, adalah berapa besar kemampuan seseorang karyawan dengan menilai, dianalisis menciptakan serta buat keputusan didalam ketuntasan masalah yang ada.

e. Kerja sama, adalah semuanya karyawan sanggup berpartisipasi dengan kerja sama dan karyawan lain dengan cara vertical atau dan horizontal dalam hingga diluar kerjaan sehingga perolehan kerjaan menjadi semakin lebih baik.

f. Kepatuhan, adalah suatu kesediaan karyawan didalam kepatuhan aturan-aturan yang dilakukan pekerjaan sesuai instruksi yang berikan kepada karyawannya. 


\section{Kerangka Berpikir}

Gambar 1. Kerangka Berpikir

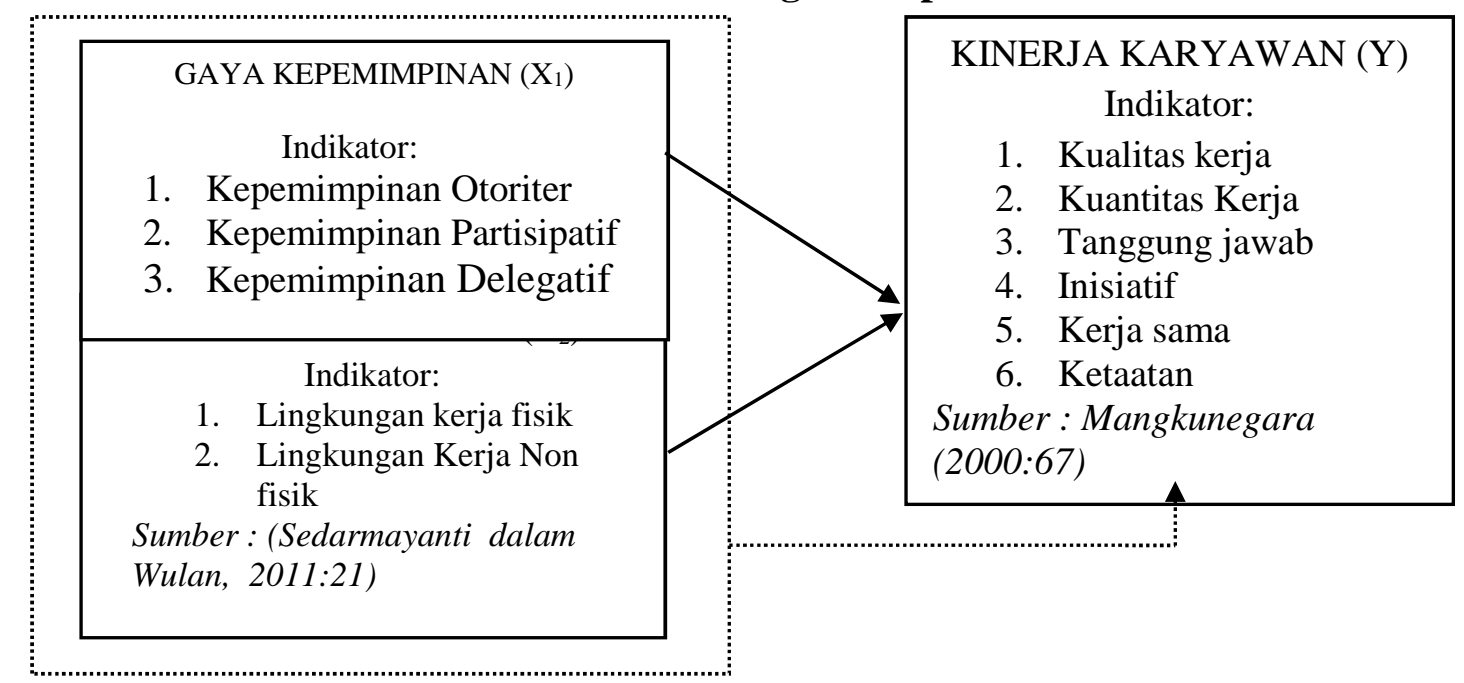

Sumber :Data diolah, (2018)

$\begin{array}{ll}\longrightarrow & =\text { Secara parsial (individu) } \\ & =\text { Secara simultan (bersama }- \text { sama) }\end{array}$

\section{Hipotesis}

Hipotesis penelitian ini adalah :

a. Gaya pemimpinan yang positif dan atau signifikan terhadap kinerjanya karyawan pada PT BPR Agro Cipta Adiguna Pare.

b. Lingkungan Kerja yang positif dan signifikan terhadap kinerjanya karyawan pada PT BPR Agro Cipta Adiguna Pare.

c. Gaya Pemimpinan dan Lingkungan Kerja yang bersama terhadap kinerjanya karyawannya pada PT BPR Agro Cipta Adiguna Pare

\section{METODE PENELITIAN}

\section{Populasi dan Sampel}

Semua karyawannya yang bekerja di PT BPR Agro Cipta Adiguna Pare.

\section{Sampel}

Sampel penelitian ini berjumlah 30 orang.

\section{Metode Pengambilan Sampel}

Peneliti mengambil metode sensus yaitu semua karyawan di PT BPR Agro Cipta Adiguna Pare sebanyak 30 orang.

Variabel Penelitian, dan Cara Pengukuran dan Definisi Operasional

\section{Variabel Penelitian}



a. Variabelnya Bebas
b. Variabelnya Terikat

\section{Cara Pengukuran}

Cara Pengukuran sangat setuju skor 5,setuju skor 4,ragu-ragu skor 3,tidak setuju skor 2,sangat tidak setuju skor 1

\section{Definisi Operasional}

Tabel 2. Definisi Operasional Variabel

\begin{tabular}{|c|c|c|}
\hline Variabel & Konsep Variabel & Indikator \\
\hline $\begin{array}{l}\text { Variabel bebas } \\
\text { (Independent) } \\
\text { Gaya Kepemimpinan } \mathrm{X}_{1}\end{array}$ & $\begin{array}{l}\text { Gaya Kepemimpinan }\left(\mathrm{X}_{1}\right) \\
\text { adalah bagaimana cara } \\
\text { mengendalikan bawahan } \\
\text { untuk melaksanakan sesuatu. } \\
\text { Putu sunarcahya (2008) }\end{array}$ & $\begin{array}{l}\text { 1. Kepemimpinan otoriter } \\
\text { 2. Kepemimpinan partisipatif } \\
\text { 3. Kepemimpinan delegatif } \\
\text { Hasibuan }(2007: 170)\end{array}$ \\
\hline $\begin{array}{l}\text { Variabel bebas } \\
\text { (Independent) } \\
\text { Lingkungan Kerja X2 }\end{array}$ & $\begin{array}{l}\text { Lingkungan Kerja (X2) dapat } \\
\text { diartikan sebagai keseluruhan } \\
\text { alat perkakas yang } \\
\text { dihadapi,lingkungan } \\
\text { sekitarnya dimana seorang } \\
\text { bekerja, metode } \\
\text { kerjanya,sebagai pengaruh } \\
\text { kerjanya baik bagi perorangan } \\
\text { maupun kelompok. } \\
\text { (Simanjutak, 2003:39) }\end{array}$ & $\begin{array}{l}\text { 1. Lingkungan Kerja Fisik } \\
\text { 2. Lingkungan Kerja Non } \\
\text { Fisik } \\
\text { Sedarmayanti dalam wulan,2011:21 }\end{array}$ \\
\hline $\begin{array}{l}\text { Variabel Terikat } \\
\text { (dependent) } \\
\text { Kinerja Karyawan Y }\end{array}$ & $\begin{array}{l}\text { Kinerja karyawan (Y) adalah } \\
\text { hasil seseorang secara } \\
\text { keseluruhan selama periode } \\
\text { tertentu didalam } \\
\text { melaksanakan tugas, seperti } \\
\text { standar hasil kerja, target atau } \\
\text { sasaran kriteria yang telah } \\
\text { ditentukan terlebih dahulu dan } \\
\text { telah disepakati bersama } \\
\text { (Veithzal,2005:97) }\end{array}$ & $\begin{aligned} & \text { 1. } \text { Kualitas kerja } \\
& \text { 2. } \text { Kuantitas kerja } \\
& \text { 3. } \text { Tanggung jawab } \\
& \text { 4. } \text { Inisiatif } \\
& \text { 5. } \text { Kerja sama } \\
& \text { 6. } \text { Ketaatan } \\
& \text { Mangkunegara (2000:67) }\end{aligned}$ \\
\hline
\end{tabular}

\section{Teknik Pengumpulan Data}

1. Survei Pendahulua

2. Studi Kepustakaan

3. Studi Lanjutan 


\section{Instrumen Pengumpulan data}

\section{Uji Validitas}

Nilainya $\mathrm{r}$ hitungnya dengan $\mathrm{r}$ tabelnya sesuai untuk tingkatan signifikasinya 5 $\%$ dari degree of freedom $(\mathrm{df})=\mathrm{n}-2, \mathrm{n}$ adalah total sampelnya. Jika $\mathrm{r}$ hitung $>\mathrm{r}$ tabelnya maka indikatornya tersebut valid, bila $\mathrm{r}$ dihitung $<\mathrm{r}$ tabelnya maka indikatornya tidak valid (Ghozali,2005)

\section{Uji Reliabilitas}

Pengukurannya reliabilitas melakukan dengan one shot saja dengan menggunakan uji SPSS dan uji statistik cronbach Alpha $(\alpha)$. Variabelnya dikatakan reliable jika memberikan nilainya Cronbach Alpha $(\alpha)>0,60$ (Ghozali,2011:46), contohnyaantara lain:

a. Reabilitasnya diuji coba hasilnya $\geq 0,60$ dengan arti, hasilnya uji coba reabilitas yang baik

b. Reabilitasnya menggunakan uji coba $<0,60$ yang artinya, hasilnya uji coba dimiliki reabilitas yang masih kurang baik

\section{Metode Analisis Data :}

\section{Uji Asumsi klasik}

\section{Uji Normalitas}

Modelnya regresi variabelnya terikat dan variabelnya bebas kedua memiliki distribusi normal atau tidak normal tidak.

\section{Uji Heteroskedastisitas}

Jika Kalau ada titiknya membentuk pola tertentu yang teratur, maka bisaterjadi heteroskedastisitasnya jika tidak ada polanya maka diatas dan bawahnya angka 0 pada sumbu Y tidak terjadi heteroskidastisitasnya. Pemimpin akan mempengaruhi orang lain sehingga untuk bekerja mencapai tujuan perusahaannya (IVAN, 2016)

\section{Uji Multikolonieritas}

Modelnya regresi ditemukan pada adanya korelasi diantara variabel bebas. Digunakan untuk Tolerance pengukuran variabilitasnya sesuai variabel bebasnya yang dipilih dan tidak bisa dijelaskan oleh variabel bebas. Jadi nilainya tolerance rendahnya sama dengan nilai VIF yang tinggi menunjukan adanya kolinearitas yang tinggi. Nilai cut off yang umum dipakai adalah nilai tolerance $<0,10$ atau sama dengan VIP $>10$. 


\section{Analisis Regresi Linier Berganda}

Analisis Regreasi Linier Berganda :

$$
\mathrm{Y}=\mathrm{a}+\mathrm{b}_{1} \mathrm{X}_{1}+\mathrm{b}_{2} \mathrm{X}_{2}+\mathrm{e}
$$

Keterangan :

$\mathrm{Y}=$ Kinerja Karyawan

X1 = Gaya Kepemimpinan

X2 = Lingkungan Keja

b1 = Koefisien regresi Gaya Kepemimpinan

b2 = Koefisien regresi Lingkungan Kerja

$\mathrm{a}=$ Konstanta

$\mathrm{e}=$ error

Analisis ini teknik mencari regresi berganda dengan menggunakan output program SPSS

\section{Uji Hipotesis}

\section{Uji t}

Rumus uji t :

$$
\text { To }=\frac{b 1}{s \cdot 1}
$$

Keterangan :

$$
\begin{aligned}
& \text { To }=\mathrm{t} \text { hitung } \\
& \mathrm{b} 1=\text { koefisien regresi } \\
& \mathrm{sb} 1=\text { standart eror }
\end{aligned}
$$

kesimpulan :

a. Bila $\mathrm{t}$ hitung $>\mathrm{t}$ table, maka hipotesa dikatakan pengaruh positif yang signifikannyadiantara gaya pemimpin (X1) terhadap kinerjanya karyawannya (Y) atau lingkungannya pekerja (X2) terhadap kinerjanya karyawannya adalah diterima.

b. Bila $\mathrm{t}$ hitungnya < table, maka hipotesanya dikatakan pengaruh positif yang signifikannya antara lain gaya pemimpin (X1) terhadap kinerjanya karyawan (Y), atau lingkungannya kerjanya (X2) terhadap kinerjanya karyawan (Y) yaitu ditolak.

\section{Uji F}

Rumus uji f :

$$
\mathrm{F}=\frac{\mathrm{R} / \mathrm{k}}{(1-\mathrm{R}) /(1-1-\mathrm{k})}
$$


Keterangan :

R2 = Koefisien korelasi berganda dikuadratkan

$\mathrm{n} \quad=$ Jumlah sampel

$\mathrm{k} \quad=$ jumlah variabel bebas

kesimpulan

a. $\quad$ F hitung $>\mathrm{f}$ table, maka hipotesa dikatakan berpengaruh positif yang signifikan antara gaya kepemimpinan (X1) dan lingkungan kerja (X2) terhadap kinerja karyawan (Y) adalah diterima.

b. F hitung < F tabel, maka hipotesa mengatakan pengaruh positif yang signifikannya antara lain gaya pemimpin (X1) dan lingkungannya kerjanya (X2) terhadap kinerjanya karyawan (Y) yaitu ditolak.

\section{Uji R2 (koefisien determinasi)}

Untuk mengetahui seberapa besar presentasenya berpengaruh langsung variabelnya yang bebas semakin mendekat hubungannya dengan variabel yang terikat atau dapat dikatakannya bahwa penggunannya modelnya tersebut dapat dibenarkan.

\section{HASIL DAN PEMBAHASAN.}

\section{Hasil Penelitian}

Jika pemimpin sekarang dapat melakukan gaya kepemimpinan sesuai keinginan dan diinginkan karyawan maka lingkungan kerja sangat mempengaruhi kinerja karyawan untuk lebih semangat lebih baik lagi pada PT BPR Agro Cipta Adiguna Pare.

\section{Deskripsi Responden}

Peneliti mengambil responden dari usia, jenis kelamin, status perkawinan dan pendidikan terakhir.

Tabel 3. Karakteristik Usia Responden

\begin{tabular}{|c|c|c|}
\hline Kategori Usia & Jumlah & \% \\
\hline $21-30$ tahun & 23 & 77,0 \\
\hline $31-40$ tahun & 7 & 23,0 \\
\hline Total & 30 & 100 \\
\hline
\end{tabular}

Sumber : Data Primer, diolah (2018)

Responden sebanyak 30 orang dengan karakteristik usia yang didominasi oleh responden berusia 21-30 tahun, sebanyak $30 \%$ 
Tabel 4. Karakteristik Jenis Kelamin Responden

\begin{tabular}{|c|c|c|}
\hline Jenis Kelamin & Jumlah & \% \\
\hline Laki-laki & 26 & 86,0 \\
\hline Perempuan & 4 & 14,0 \\
\hline Total & 30 & 100 \\
\hline
\end{tabular}

Sumber : Data Primer, diolah (2018)

Responden sebanyak 30 orang dari kalangan laki-laki, sebanyak $86 \%$.

Tabel 5. Status Perkawinan Responden

\begin{tabular}{|c|c|c|}
\hline Status & Jumlah & \% \\
\hline Kawin & 22 & 73,3 \\
\hline Belum Kawin & 8 & 26,6 \\
\hline Total & 30 & 100 \\
\hline
\end{tabular}

Sumber : Data Primer, diolah (2018)

Responden sebanyak 30 orang dengan karakteristik status perkawinan yang didominasi oleh responden dengan status kawin sebanyak 73,3\%

Tabel 6. Karakteristik Pendidikan Terakhir Responden

\begin{tabular}{|c|c|c|}
\hline Strata Pendidikan & Jumlah & \% \\
\hline SMP & 1 & 3,3 \\
\hline SMA & 9 & 30 \\
\hline DI & 2 & 6,6 \\
\hline DII & 2 & 6,6 \\
\hline DIII & 5 & 16,6 \\
\hline S1 & 11 & 33,3 \\
\hline Total & 30 & 100 \\
\hline
\end{tabular}

Sumber : Data Primer, diolah. (2018)

Responden dalam penelitian ini ada sebanyak 30 orang dengan karakteristik pendidikan yang didominasi oleh responden berpendidikan S1, sebanyak 33,3\%.

\section{Uji Instrument Penelitian}

Uji Instrument meliputi uji Validitas ini yaitu Korelasi Product a Moment dari Pearson tingkat kepercayaan 95\% $(\alpha=0,05)$ dilaksanakan dengan cara mengkolerasikan skor masing-masing item dengan skor totalnya. Sementara instrument dikatakan mempunyai Realibilitas apabila instrument cukup digunakan sebagai alat pengumpul data.

\section{Hasil Uji Realibilitas Instrumen}

Hasil uji realibilitas koefisien Alpa diatas 0,60 dikatakan pengukuran masingmasing variabel dari kuesioner yaitu realibel sehingga item konsep variabel layak dipakai sebagai alat ukur. 


\section{Uji Asumsi Klasik}

\section{Uji Multikolinieritas}

Gejala multikolinieritas dilihat dari nilai tolerance dan nilai Varian Inflation Factor (VIF).

\section{Hasil Uji Multikolinieritas}

Nilai VIF variabel bebas penelitian $<10$ dan nilai toleransi variabel bebas lebih dari $10 \%$ berarti tidak terjadi korelasi antar variabel bebas yang nilainnya lebih dari $90 \%$ bahwa tidak terdapat gejala multikollinieritas antar variabel bebas dalam model regresi.

\section{Uji Heterokedastisitas}

Uji heterokedastisitas menggunakan metode grafik Scatterplot.

\section{Normalitas}

A. Grafik Histogram

Data dikatakan normal bila bentuk grafik memiliki kemiringan yang cenderung imbang, baik dari sisi kiri atau sisi kanan, dan grafik berbentuk hampir sempurna(Nugroho,2005).

\section{Gambar 2. Hasil Pengujian Normalitas}

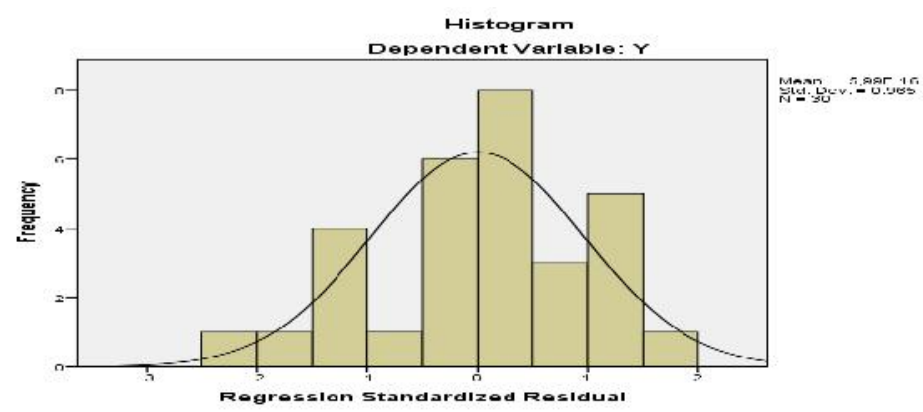

Sumber : lampiran output SPSS (2018)

Dapat dilihat bahwa hasil dari grafik histogram diatas tepat pada tengahtengah titik nol membagi 2 sama besar dan tidak memenceng ke kanan maupun ke kiri.

B. GrafikNormal Probability Plot

Data dibilang normal bila titik data menyebar sekitar garis diagonal dan mengikuti arah garis diagonal

\section{Analisa Regresi Berganda}

Persamaan regresi linier berdasarkan standardized sebagai berikut :

$$
\mathrm{Y}=2,253+0,203 \mathrm{X} 1+0,199 \mathrm{X} 2+\mathrm{e}
$$

Dari persamaan tersebut diatas maka dapat diiterprestasikan bahwa : 
1. Konstanta (a) $=2,253$ artinya apabila tidak ada perubahan gaya kepemimpinan dan lingkungan kerja $\left(\mathrm{X}_{1}+\mathrm{X}_{2}=0\right)$, maka kinerja karyawan $(\mathrm{Y})$ sebesar 2,253 satuan.

2. Koefisien regresi $X_{1}\left(b_{1}\right)=0,203$ artinya bila gaya kepemimpinan naik sebanyak satu satuan, kinerja karyawan (Y) meningkat sebesar 2,253 satuan, dengan asumsi bahwa variabel bebas yang lain konstan atau tidak berubah $\left(\mathrm{X}_{2}=0\right)$.

3. Koefisien regresi $X_{2}\left(b_{2}\right)=0,199$ artinya jika lingkungan kerja naik sebanyak satu satuan, kinerja karyawan(Y) meningkat sebesar 0,199 satuan, dengan asumsi bahwa variabel bebas yang lain konstan atau tidak berubah $\left(\mathrm{X}_{1}=0\right)$.

\section{Pengujian Hipotesis}

Uji t

Hasil penelitian uji t bahwa:

1. Secara parsial variabel gaya kepemimpinan (X1) berpengaruh signifikan terhadap Kinerja Karyawan (Y). Angka signifikan gaya kepemimpinan 0,003 dimana angka $<$ dari 0,05 berarti menolak Ho dan Ha, juga mempunyai nilai Uji t = 3,232artinya variabel gaya pemimpin yang miliki berpengaruh terhadap signifikan parsial yaitu 3,232 terhadap kinerjanya karyawannya (Y).

2. Secara parsial variabelnya lingkungan kerja (X2) terpengaruh signifikannya terhadap kinerjanya karyawannya (Y). Angkanya yang signifikan lingkungannya kerja yaitu 0,001 dimana angkanya < dari 0,05 berarti ditolak Ho dan Ha, nilainya Uji $\mathrm{t}=3,730$ artinya variabelnya lingkungan kerjanya memiliki pengaruh yang signifikan secara parsial yaitu 3,730 terhadap kinerjanya karyawannya (Y).

\section{Uji F}

Uji F variabel dimasukan di model secara simultan mempengarui terhadap variabel terikat digunakan uji $\mathrm{F}$

Pada Uji F menunjukkan Fhitung sebesar 48,617 (Fsig=0,000).Jadi Fsig(0,000< 0,05), berarti diterima bentuk persamaan $\mathrm{Y}=\mathrm{a}+\mathrm{b} 1 \mathrm{X} 1+\mathrm{b} 2 \mathrm{X} 2$ diterima, arti simultannya yaitu variabel $\mathrm{X} 1$ dan $\mathrm{X} 2$ terpengaruh terhadap variabelnya $\mathrm{Y}$.

Dasar hasil dari signifikannya uji $\mathrm{F}$ variabelnya bebas (X1 dan X2) < dari signifikan $\alpha(0,05)$ Menunjukkan hipotesis diterima.

\section{Koefisien Determinan (R2)}

Koefisien determinasi dipakai untuk menunjukkan proporsi variable dependen dijelaskan variabel independen. Apabila R2 mendekati angka satu berarti terdapat hubungan yang kuat. 
Koefisien Determinan (R2) dapat dijelaskan korelasi antara variabel bebas dengan variabel terikat ditunjukkan oleh besarnya Multiple $\mathrm{R}$ yaitu 0,789 dimana nilai korelasi ini mendekati 1, sehingga hubungan diantara gayanya pemimpin (X1), dan lingkunganya kerja (X2) dan kinerjanya karyawannya (Y) yaitu kuat dan searah.

Koefisien yang determinannya (R) squarenya sebesar 0,783 artinya besar terpengaruh gayanya pemimpin (X1), dan lingkungannya kerjanya (X2) terhadap kinerjanya karyawannya (Y) pada PT BPR Agro Cipta Adiguna Pare sebesar 78,3\%, sisanya terpengaruhi oleh variabel yang lain tidak termasuk dalamnya pembahasan dan penelitiannya ini

\section{Pembahasan}

Setelah melakukan penelitian pada PT BPR Agro Cipta Adiguna Pare terhadap 30 karyawan, penulis mendapatkan data yang dijadikan analisa. pengaruhnya variabelnya menjelaskan antara lain :

1. Pengaruhnya Gayanya pemimpin terhadap Kinerjanya Karyawan

Nilainya t dihitung 3,232 signifikansinya hasilnya 0,003 tersebut $<0,05$, berarti $\mathrm{Ha}$ diterima dan Ho ditolak.

2. Pengaruhnya Lingkungannya Kerja terhadap Kinerjanya Karyawan

Nilai t hitungnya 3,730 signifikansi hasilnya 0,001 tersebut $<0,05$, berarti bisa diterima Ha dan menolak Ho.

3. Pengaruhnya Gayanya Kepemimpinannya dan Lingkungan Kerjanya Secara Simultan terhadap Kinerjanya Karyawan

Hasil dari pengujian Nilainya f hitungnya 48,617 signifikansinya 0,000 tersebut < 0,05. Pengujiannya membuktikan Gayanya pemimpin dan Lingkungannya Kerja terpengaruh positif dan signifikansinya terhadap kinerjanya karyawan.

Hasil uji determinasi variabel independen terhadap variabel dependen (R2) yaitu $78,3 \%$. informasi $21,7 \%$ dari kinerja karyawan dipengaruhi faktor lain yang tidak disebutkan.

Dari analisa diatas perannya gaya kepemimpinannya dan lingkungannya kerja terhadap kinerjanya karyawan yang besifat positif. 


\section{KESIMPULAN DAN SARAN}

\section{Kesimpulan}

Berdasarkan peneliti mengambil judulnya "Pengaruh Gaya Kepemimpinan dan Lingkungan Kerja terhadap Kinerja Karyawan pada PT BPR Agro Cipta Adiguna Pare". Hasil dari penelitian ini disimpulkan yaitu :

1. Ada pengaruh gaya pemimpin terhadap kinerjanya karyawan pada PT BPR Agro Cipta Adiguna Pare.ujinya $\mathrm{t}$ parsial variabel gaya kepemimpinannya (X1) terpengaruh signifikan terhadap kinerjanya karyawan. Angkanya signifikan gaya pemimpin 0,003 dimana angkanya tersebut melebihi kecil dari angka 0,05 berarti ditolak Ho dan Ha, nilai uji $\mathrm{t}=3,232$ artinya variabelnya gaya kepemimpinannya memiliki pengaruh yang signifikannya parsial 3,232 terhadap kinerjanya karyawan (Y)

2. Uji t parsial variabel lingkungan kerja (X2) berpengaruh signifikan terhadap kinerja karyawan (Y). Angka signifikan lingkungan kerja 0,001 dimana angka tersebut < 0,05 yang berarti menolak Ho dan $\mathrm{Ha}$, nilai uji $\mathrm{t}=3,730$ artinya variabel lingkungan kerja berpengaruh signifikan secara parsial 3,730 terhadap kinerja karyawan (Y).

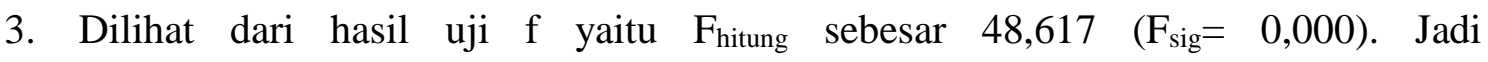
$\mathrm{F}_{\text {sig }}(0,000<0,05)$, berarti model diterima atau dapat disimpulkan bahwa bentuk persamaan $\mathrm{Y}=\mathrm{a}+\mathrm{b} 1 \mathrm{X} 1+\mathrm{b} 2 \mathrm{X} 2$ bisa diterima, secara simultan artinya variabel gaya kepemimpinannya (X1) dan (X2) berpengaruh terhadap variabel kinerja karyawan $(\mathrm{Y})$

\section{Saran}

Peneliti memberikan saran sebagai berikut :

\section{Untuk Perusahaan}

a. Terus melakukan evaluasi kinerja karyawan karena hal ini sangat penting untuk mengetahui efektif atau tidaknya sistem gaya kepemimpinan yang dijalankan perusahaan

b. Pergantian pimpinan sebaiknya jangan dilakukan terlalu sering karena jika terlalu singkat masa pergantiannya akan membuat karyawan sulit untuk beradaptasi dengan suasana lingkungan kerja yang baru. Hal ini menghasilkan kinerja yang 
kurang efisien karena terlalu sulitnya beradaptasi dengan suasana lingkungan kerja yang cepat berganti dan menimbulkan ketidaknyamanan karyawan.

2. Untuk Peneliti selanjutnya

Penelitian ini sebaiknya dikembangkan dengan mengganti atau menambah variabel selain gaya kepemimpinan, lingkungan kerja dan kinerja karyawan.

\section{DAFTAR PUSTAKA}

Darumeutia.Anisah. (2017). PENGARUH GAYA KEPEMIMPINAN DAN LINGKUNGAN KERJA TERHADAP KEPUASAN KERJA PEGAWAI PT PLN (PERSERO)UNIT INDUK PEMBANGUNAN JAWA BAGIAN TENGAH 11.

Dessler, Gary. 2015. Manajemen Sumber Daya Manusia, Jakarta: Salemba Empat. Handoko, T. Hani. 2015. Manajemen, Yogyakarta: BPFE - Yogyakarta.

Handoyo laura natalia, Hamid Djamhud, I. (2015). THE INFLUENCE OF LEADERSHIP STYLE ON EMPLOYEE"S PERFORMANCE THROUGH WORK MOTIVATION (AN ORGANIZATION STUDY AT FOUR HOTELS IN MALANG, 22(1).

Indrawijaya, Adam Ibrahim dan Suprapti Wahyu. 2008. Kepemimpinan Dalam Organisasi. Jakarta: Lembaga Administrasi Negara Republik Indonesia.

IVAN, S. A. (2016). PENGARUH KEPEMIMPINAN ,MOTIVASI DAN LINGKUNGAN KERJA TERHADAP KINERJA,KARYAWAN (STUDI PADA PT PERKEBUNAN NUSANTARA VII PEMATANG KAWAH NATAR.

Kasmir. 2016. Manajemen Sumber Daya Manusia, Jakarta : PT Bumi Aksara Langi, S. R., Saerang, D. P. E., \& Worang, F. G. (2015). THE IMPACT OF LEADERSHIP STYLE, WORK MOTIVATION , AND JOB SATISFACTION ON EMPLOYEE PERFORMANCE ( BANK BNI KAWANGKOAN BRANCH ), 15(5), 473-484.

Mariam, Rani. 2009. Pengaruh Gaya Kepemimpinan dan Budaya Oragnisasi Terhadap Kinerja Karyawan Melalui Kepuasan Kerja Karyawan Sebagai Variabel Intervening. Skripsi. Skripsi disajikan pada Google Shcolar, 05 februari 2018. Online tersedia: http//www.googlescholar.com, diunduh pada 28 januari 2018

Nawawi, Hadari. 2006. Manajemen Sumber Daya Manusia untuk Bisnis Yang Kompetitif. Yogyakarta: Gadjah Mada University Press.

Putra, Dwitya. 2017. Bank Perkreditan Rakyat. Online, tersedia: http://infobanknews.com/BPR-2017/. Diunduh 30 Januari 2018.

Putra, Febri Arin, Musad mochammad al, mayowan yuniadi. (2016). TERHADAP KINERJA ( Studi pada Karyawan Perusahaan Daerah Air Minum ( PDAM ) Kota Malang ), 40(2).

Putra, Yudiarto Perdana, heryanto, B. (2017). PEMETAAN KEPEMILIKAN BADAN HUKUM DAN TINGKAT PENGGUNAAN TEKNOLOGI INFORMASI PADA UMKM ( Studi Pada Kelurahan Pojok Kecamatan Mojoroto - Kota Kediri ). EKONIKA, 2(2), 183-197. https://doi.org/http://dx.doi.org/10.30737/ekonika.v2i2.44

Rahayu, B., \& Ruhamak, M. D. (2017). Pengaruh Kepemimpinan, Insentif, Remunerasi Dan Motivasi Terhadap Kinerja Karyawan (Studi Kasus Pada PT Industri Sandang Pangan Nusantara Cilacap). EKONIKA, 2(1), 1-22. 
https://doi.org/http://dx.doi.org/10.30737/ekonika.v2i1.15

Ratih,E.A. 2015. Pengaruh Gaya Kepemimpinan dan lingkungan kerja terhadap kinerja karyawan; Vol.4, 1-10 Stiesia Surabaya

Rahadi, Dedi Rianto. 2010. Manajemen Kinerja Sumber Daya Manusia, Malang: Tunggal Mandiri Publishing.

Reza, Regina Aditya. 2010. Pengaruh Gaya Kepemimpinan, Motivasi, dan Disiplin Kerja Terhadap Kinerja Karyawan PT Sinar Sentosa Perkasa Banjarnegara. Skripsi. Skripsi disajikan pada Google Shcolar, 06September 2011. Online tersedia: http//www.googleshcolar.com, diunduhpada 28 Januari 2018.

Rivai, Veithzal \& Deddy Mulyadi. 2011. Kepemimpinan dan Perilaku Organisasi. Jakarta: Raja Grafindo Persada

Satriyono, G. (2017). ANALISIS KEMAMPUAN KEPEMIMPINAN TERHADAP

KINERJA DOSEN PADA UNIVERSITAS KADIRI. JURNAL EKOMAKS, 6(1).

Santoso. 2010. Statistik Parametrik Konsep dan Aplikasi dengan SPSS. Jakarta:PT Gramedia

Sanusi. 2011. Metodologi penelitian bisnis. Jakarta: Salemba Empat

Sugiyono. 2008. Metode Penelitian Kuantitatif, Kualitatif dan $R$ \& D, Bandung: Alfabeta.

Suminar,A.C., Mukzam,M.D., dan Ruhana, Ika (2015). Jurnal Pengaruh Gaya Kepemimpinan Dan Lingkungan Kerja Terhadap Kinerja ; Vol. 26, 1 - 10 Universitas Brawijaya www.infobanknews.com_2017(diakses pada tanggal 25 januari 2018)

Suwignyo, Angga. 2017. Gaya kepemimpinan dan lingkungan kerja terhadap kinerja karyawan; Vol.15, 1-7 Akademika

Wahyu, Noor.2014. Uji Validitas Dan Reabilitas. Online, tersedia : http://qmc.ac.id/2014/11/01/u-j-i-va-l-i-d-i-t-a-s-d-a-n-r-e-a-b-i-l-i-t-a-s.

Diunduh 28 September

Widodo, D. S. (2014). Influence of Leadership And Work Environment To Job

Satisfaction And Impact To Employee Performance ( Study On Industrial

Manufacture In West Java ), 5(26), 2010-2015. 